\title{
Research on the construction of diversified teaching evaluation system in English teaching quality management in Higher Vocational Colleges
}

\author{
JU Zeng, LI Jihong \\ chongqing Chemical Industry Vocational college,Chongqing 401228,China
}

Keywords: higher vocational colleges; English teaching; diversified teaching evaluation system

\begin{abstract}
In recent years due to the social development of the new requirements for talents, vocational colleges teaching reform carried out to cultivate high-quality comprehensive talents, innovation as the purpose of teaching, and under the guidance of this course of teaching method reform and innovation, but the teaching evaluation system is still use the previous evaluation method hinder the improvement of teaching quality. Higher Vocational College Students' English level is relatively weak, and many teachers lack in teaching methods, evaluation system reform of colleges and universities and the relatively large gap, this paper mainly analyzes the diversified teaching evaluation system, and combined with the present situation of English Teaching in higher vocational colleges, puts forward the significance and methods of constructing diversified teaching evaluation system.
\end{abstract}

\section{Introduction}

As an important means to evaluate the students' knowledge and enthusiasm, the teaching evaluation system has a great influence on the students' enthusiasm for learning. With the internationalization and informationization, occupy the English Teaching in the training of the more important position, the traditional English teaching evaluation mainly to the basic knowledge of the language, each stage of the examination scores as the main standard, as a result of an exam, there are many defects, so it is imperative to construct diversified teaching evaluation system.

\section{Diversified teaching evaluation system}

Meaning and purpose. "Evaluation" refers to an "single evaluation", the evaluation of diversification, through a variety of evaluation methods to evaluate behavioral changes occurred during the evaluation of students' learning process and the learning process of students, including the progress, specific performance, emotion, attitude and learning strategies [1]. The main purpose of the diversified evaluation is to encourage students to actively participate in the learning process, learning behavior and guide students to control their feelings, and help students to establish a sense of achievement, which makes the learning self confidence and positive change for the evaluation of the participants and their evaluation. Different from the single evaluation system, evaluation of students pay more attention to the diversification of value, make the students through the evaluation results to take the initiative to find their own learning problems, and constantly adjust and improve learning methods, help to promote teaching reform, the English teaching situation by the teacher to grasp the whole, to improve the quality of English Teaching in Higher Vocational colleges.

Evaluation principle. The principle of apply more teaching evaluation methods, diversified evaluation, diagnostic evaluation and summative evaluation, according to different occasions, the use of evaluation methods are also different. When the teacher evaluates the students' English learning, it is necessary to make clear the purpose of the evaluation and the specific needs of the teaching, so as to select the appropriate evaluation methods. In the process of evaluation, teachers should pay more attention to personality, students, self consciousness and basic level, the students' learning attitude and participation as the evaluation factors, to supervise the quality of teaching, guide the teaching direction of the. Cooperative principle, in teaching evaluation, teachers and students between the close cooperation, good communication, to select the best evaluation point, can mobilize the 
enthusiasm of the students, at the same time to participate in the self evaluation and group evaluation to. Teachers in the formulation of standards and evaluation scheme, should pay full attention to the students' suggestions, combined with teaching experience, often carry out evaluation demonstration and explanation, make students form the habit of constantly self reflection in their daily learning, and constantly correct learning attitude, change the learning methods, to enable students to experience the real "master" feeling, eliminate the students' concerns and psychological conflict [2]. Diversification principle, in order to make the evaluation more scientific, reasonable and fair, need to diversify from multiple perspectives. First, the diversity of evaluation subjects. In the evaluation, changes in the traditional teacher as the only evaluation of the main method, to promote students, students, parents and parents to participate in the rating; second, the evaluation of the diversity of content. In addition to evaluating students' skills and knowledge, the students' learning habits, attitudes and methods should be evaluated. Finally, the diversity of evaluation methods should be taken into consideration. Change the written examination of the traditional evaluation method, interview, interview, increase classroom performance records, assignments completion of various evaluation methods, the comprehensive use of diagnostic evaluation, process evaluation and summative evaluation etc.. The principle of inspiration, in the diversification of evaluation, teachers must understand the purpose of the evaluation is to promote the learning of the students, thus to implement the incentive principle, guarantee the students' emotion, attitude and motivation is always positive, stimulate their interest in learning, the students' achievements are affirmed, and encourage students to a better learning goals down forward.

\section{The problems of English Teaching in Higher Vocational Colleges}

The higher vocational colleges in teaching methods, teaching contents and teaching evaluation etc. many college students copy, but the two sides have great differences in the cultural level, ability to accept knowledge master class, so the problems existing in the teaching of Higher Vocational Colleges in recent years, personnel training is more and more prominent; at the same time by the enterprises for talents is also presented more stringent requirements, so more and more vocational colleges began to carry out the teaching reform, the teaching reform of Higher Vocational Colleges in recent years and achieved remarkable results, but there are also some problems.

Students are poor in English and despise the learning of culture. Higher vocational college students as the main part of technical secondary school, high school students and five college students, these students are relatively weak, and more inclined to learn a skill, therefore corresponds to the interest in learning is not high, some students even don't want to offer English and other cultural programs to save more time learning skills therefore, this kind of students in learning English is only to cope with the examination or inspection, and ignore the importance of English knowledge in the work of the future.

Teachers are weak. The number of students in higher vocational colleges is increasing, leading to the original College English teachers' work more arduous task, while new teachers either teaching experience or professional level and ordinary colleges and universities have a larger gap, although in recent years the recruitment of teachers in Higher Vocational Colleges conditions improved constantly, but also unable to cope with the problem of teachers' lack of experience and teaching personnel flow big [3].

The teaching evaluation system is single. Although most of the higher vocational institutes began teaching reform, many factors but by teaching funds, teachers and other constraints, cultural lessons still in class teaching, teachers as the main mode of teaching, to improve students' English proficiency has little effect; with the increase of the student scale, increase working strength of English teachers in higher vocational colleges, so they don't willing to choose diversified evaluation methods, single evaluation system and more willing to choose a simple, convenient, in an exam, easy to complete the teaching task. 


\section{The importance of diversified teaching evaluation system to improve the quality of English Teaching}

Improve the quality of students. Through the diversified teaching evaluation can improve students' interest in learning, to make it more accurate understanding of the learning task, and constantly adjust the direction and methods of learning, students' interest in learning, enhance English subtle. To build a diversified evaluation system to promote the students subject position, so students can feel valued, to enjoy the process of learning, can give full play to the initiative, self evaluation and problem solving ability has been improved obviously, the changes to better respond to future work.

It is helpful to improve the teaching level of Teachers. The method of teaching evaluation diversification appears to increase the teacher's task, in fact, to a large extent reduce the teacher's teaching task, through the evaluation stage and multi subject, teachers will focus more on the students' daily learning control, reduce the workload of the end of the semester, through the study of three teachers; the interaction between tasks and students, and classroom subject position to students, reduce the amount of classroom instruction, only need to guide students and to guide. On the other hand, through diversified evaluation, teachers can find mistakes in their own teaching process, find and choose better teaching methods, and improve their teaching level.

It is helpful to improve the quality of English Teaching. Diversified evaluation system can make the English teaching process is supervised and adjusted, all links between the smooth connection, avoid one-sided evaluation [4]; diversified evaluation and students as the main body, the learning power increased, but not fully accommodate diversified evaluation students, but for students to make high requirements, to enable students to improve their learning ability with the continuous improvement in the level; by participating in the self-evaluation, students more directly face their lack of learning and needs improvement, can take the initiative to seek solutions, active learning to better realize self value, and ultimately improve the quality of English teaching.

\section{The method of constructing diversified teaching evaluation system}

In the construction of diversified teaching evaluation system, teachers should improve and strengthen the incentive evaluation function, weakening the screening and selection and appraising function, and pay attention to students' academic achievement and other potential, will be included in the process of students' growth and development of the evaluation content, evaluation method is simple to adopt flexible and diverse more effective and science.

Enrich the content and form of classroom evaluation. At the beginning of each class or the end of the investigation and evaluation of teachers, students master the knowledge on this section or section, timely understanding of students' learning, grasp and use the knowledge of English level and ability, and pay attention to students' learning attitude and emotion, teachers can be mastered through discussion, homework, tests, interviews and investigation in many ways, fully integrated evaluation, knowledge and ability evaluation methods of self-assessment and peer assessment method, class and class, a detailed record of the students' learning attitude, enthusiasm and answer the question number, whether to comply with classroom discipline, group task situation, teachers can organize the students to fill in the questionnaire in a week of reflection. Self evaluation in the end of each month; carry out [5] forum, the mutual evaluation and reflection between students.

Record the growth files and record the growth of students. The formation of a daily record of teachers can organize the students to collect the usual habits, learning situation, achievement and growth through the archives such as living conditions, including homework, teachers and parents on the learning situation of the evaluation, activity recording, their view of learning, attitude and self evaluation, make students through the establishment of more comprehensive archives the true understanding of their own change and progress, so as to increase the confidence of learning, to enjoy 
the joy of success, and through continuous reflection to adjust the improper behavior in the process of learning.

Positive evaluation of students, to motivate the main. Each of the students because of the different knowledge, ability to grasp the acceptance, thus obtained in each test results are not the same, however, teachers should pay more attention to students' performance in the learning process and effort, to get good grades of students praise and evaluation of sincere, and for some of the learning result is not too ideal at the same time, as far as possible to encourage and stimulate students' interests and hobbies. In the process of teaching, we find the potential and strengths of students, teach students in accordance with their aptitude, and make them more confident in their study.

Establish a diversified evaluation of the main body and system. Different from the traditional single evaluation system, promote the diversification of evaluation system under the guidance of teachers, students, parents and students will be incorporated into the military into evaluation system, the subjects involved in the construction of the evaluation system. In the daily learning process, students answer questioning or group cooperation, by group members or other students to evaluate [6]; parents regularly evaluate students' record growth record, at the end of the semester, parents completed learning situation, life performance evaluation of students in parents will notice, to help teachers improve daily learning evaluation, so as to establish a comprehensive evaluation system, grid, mobilize the enthusiasm of students to participate in the evaluation, to make it more consciously involved in the learning process.

Improve the examination form, establish a public rating system. Before the mid-term and final examination is mainly composed of a written examination and interview results, in the period of the written exam to occupy $70 \%$, many students cramming before the exam, take short-term memory to get good grades, English learning effect is poor. In order to change this problem, new forms of examination can be added, which will be regarded as an assessment content, and will be regarded as the standard of activities participation, homework delivery, learning attitude and class discipline. The evaluation system must be open and fair, teachers can encourage the establishment of evaluation mechanism between students, such as personal achievement vertical comparison between students of supervision and evaluation, to enable students to exchange roles, into the English learning atmosphere, so as to ensure the openness of the grades. After the students' examination results come out, the teacher can encourage the students to raise objections to the places where they have questions and evaluate them with each other so as to achieve an open and fair result.

\section{Concluding remarks}

Diversified evaluation system pay more attention to the evaluation of students' learning process, learning attitude, learning ability, learning through multiple channels to student's information collection, the teachers to grasp the dynamic change of students, and constantly adjust the learning methods and strategies to promote teachers' teaching level; the evaluation system can mobilize the enthusiasm of learning the students, so that students in professional skills and communication ability to communicate in English for occupation, moving jobs help students better, improve the quality of English Teaching in higher vocational colleges is more prominent, so it is worthy to be popularized in Higher Vocational colleges.

\section{Acknowledgements}

Topic: Reform and practice of Higher Vocational English curriculum evaluation system based on promoting learning mechanism.

Project level: General Municipal Affairs of Chongqing.

Subject number: 163278. 


\section{References}

[1] Hou Zhirong. Research on the application of diversity evaluation in Higher Vocational English teaching [J].2013, (02): 62-63.

[2], Wang Zhi. Empirical Study on quality management and multiple evaluation of English Teaching in Higher Vocational Schools [J]. Journal of Tianjin Business School of Career Academy, 2013, (4): 60-63.

[3] Chen Bing. Research on the diversification of English Teaching in Higher Vocational Education [J]. Journal of Henan University of radio and television, 2015, (1): 92-94.

[4] Wang Xuemei. English Major Postgraduates assessment and academic competence development J. Journal of PLA Foreign Languages Institute, 2008, (3): 6368

[5], Lu Yi. Construct a diversified teaching evaluation system to promote the quality management of English Teaching in Higher Vocational Colleges [J]. Journal of science and technology innovation, 2013, (19): 175.

[6], Li Qiu. Theory and function of diversified evaluation system for College English Teaching [J]. Science and technology education, 2009, (33): 141-142 